Оригинальные статьи / Original articles

https://doi.org/10.18619/2072-9146-2021-5-59-63 УДК 633.88:631.529(479.2)

В.P. Тхаганов,

Т.В. Мироненко,

Т.Г. Кадацкая

Федеральное государственное бюджетное научное учреждение «Всероссийский научноисследовательский институт лекарственных и ароматических растений»

(Северо-Кавказский филиал)

353225, Россия, Краснодарский край, Динской район, ст. Васюринская, пос. ЗОС ВНИИЛР

Конфликт интересов. Авторы заявляют об отсутствии конфликта интересов.

Вклад авторов: Все авторы участвовали в планировании и постановке эксперимента, а также в анализе экспериментальный данных и написании статьи.

Для цитирования: Тхаганов В.Р., Мироненко Т.В., Кадацкая Т.Г. Интродукционное изучение гиностеммы пятилистной (Gynostemma pentaphyllum (Thunb.) Makino) в условиях Западного Предкавказья. Овощи России. 2021;(5):59-63. https://doi.org/10.18619/20729146-2021-5-59-63

Поступила в редакцию: 28.07.2021

Принята к печати: 09.09.2021

Опубликована: 11.10 .2021

Vitaly R. Tkhaganov,

Tatiana V. Mironenko,

Tatiana G. Kadatskaya

All-Russian Research Institute of Medicinal and Aromatic Plants" (North Caucasus branch) village ZOS VNIILR, Vasyurinskaya station, Dinskoy district, Krasnodar Territory, Russia, 353225

Conflict of interest. The authors declare no conflict of interest.

Authors' Contribution: All authors contributed to the planning and setting up the experiment, as well as in the analysis of experimental data and writing of the article.

For citations: Tkhaganov V.R., Mironenko T.V. Kadatskaya T.G. Introduction study of Gynostemma pentaphyllum (Thunb.) Makino in the conditions of the Western Caucasus. Vegetable crops of Russia. 2021;(5):59-63. (In Russ.) https://doi.org/10.18619/2072-91462021-5-59-63

Received: 28.07.2021

Accepted for publication: 09.09.2021

Accepted: 11.10.2021
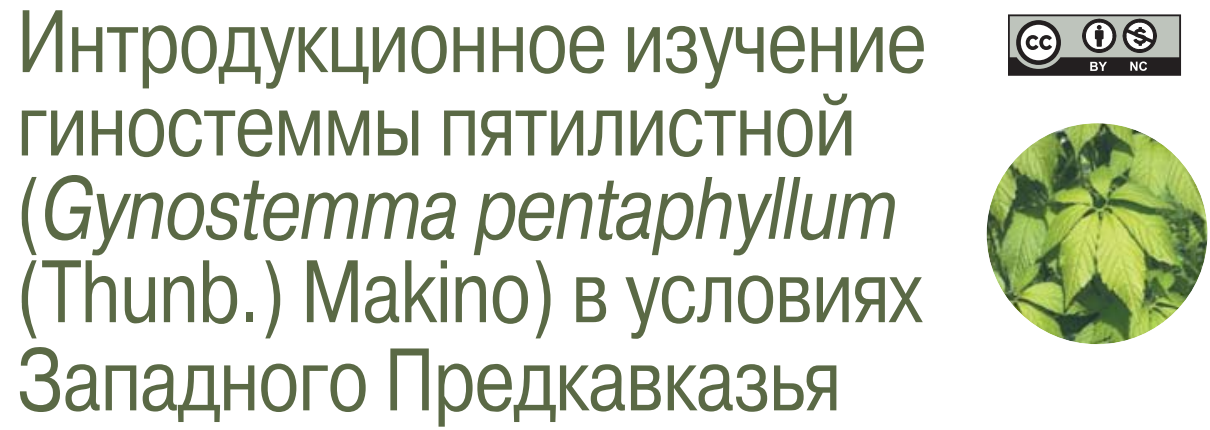

Резюме

Актуальность. В связи с тем, что гиностемма - эндемическое растение, обеспечение фармацевтической промышленности отечественным сырьем не представляется возможным, решить эту проблему можно только за счет введения данного вида в культуру.

Материал и методика исследований. Проведены исследования по интродукции гиностеммы пятилистной (Gynostemma pentaphyllum (Thunb.) Makino) на опытных полях лекарственного севооборота Северо-Кавказского филиала ФГБНУ ВИЛАР, расположенных в зоне Западного Предкавказья, с целью изучения биоморфологических и экологических особенностей роста и развития растения, выявления наиболее оптимальных условий выращивания и определения хозяйственно ценных показателей. Размножение проводили через рассаду из семян, полученных по договору из Южной Кореи, которая высаживалась в открытый грунт в начале мая на участках с прямым солнечным освещением и под пологом деревьев (затенение). Гиностемма пятилистная - это вьющаяся лиана с ползучим стеблем, поэтому она выращивалась как шпалерная культура.

Результаты. Установлено, что гиностемма в условиях Краснодарского края проходит все стадии фенологического развития, начиная с первого года вегетации, ежегодно растет и плодоносит. Определена продолжительность вегетационного периода от 229 до 238 суток. Уборку урожая проводили в фазу бутонизации - начала цветения. Наиболее оптимальным условием для выращивания данной культуры является затенение в сравнении с вариантом прямого солнечного освещения, где наблюдалось значительное усиление роста и развития гиностеммы, что способствовало значительному приросту урожайности. На корневище гиностеммы II и III года вегетации образуются новые дополнительные побеги, количество которых значительно выше в варианте при затенении. Проведенные интродукционные исследования свидетельствуют о возможности культивирования гиностеммы пятилистной в зоне Западного Предкавказья.

Ключевые слова: Gynostemma pentaphyllum (Thunb.) Makino, размножение, фенологические фазы, биометрические показатели, урожайность

\section{Introduction study of Gynostemma pentaphyllum (Thunb.) Makino in the conditions of the Western Caucasus}

Abstract

Relevance. Due to the fact that gynostemma is an endemic plant, providing the pharmaceutical industry with domestic raw materials is not possible, this problem can be solved only through the introduction of this species into the culture.

Material and methods. Studies on the introduction of Gynostemma pentaphyllum (Thunb.) Makino in the experimental fields of medicinal crop rotation of the North Caucasus branch of FGBNU VILAR, located in the zone of Western Ciscaucasia, were carried out to study the biomorphological and environmental features of growth and development of the plant, the most optimal conditions for growing and determination of economically valuable indicators. Propagation was carried out through seedlings from seeds received under the contract from South Korea, which were planted in the open ground in early May in areas with direct sunlight and under the canopy of trees (shade). Gynostemma pentaphyllum is a climbing liana with a creeping stem, so it was grown as a trellised crop.

Results. It has been established that gynostemma under Krasnodar Territory conditions passes all stages of phenological development, starting from the first year of vegetation, grows and bears fruit every year. The duration of the growing season from 229 to 238 days was determined. Harvesting was carried out in the phase of budding - beginning of flowering. The most optimal condition for growing this crop is shading compared to the option of direct sunlight, where there was a significant increase in growth and development of gynostemma, which contributed to a significant increase in yield. On the rhizome of gynostemma II and III years of vegetation new additional shoots are formed, the number of which is significantly higher in the variant with shading. The conducted introduction studies indicate the possibility of cultivation of Gynostemma pentaphyllum (Thunb.) Makino in the zone of the Western Caucasus.

Keywords: Gynostemma pentaphyllum (Thunb.) Makino, reproduction, phenological phases, biometric indicators, yield 


\section{Введение}

\section{Introduction} последние годы повышается интерес к лекарствениммуномодулирующими свойствами, позволяющими повышать адаптацию человеческого организма к воздействию неблагоприятных факторов окружающей среды. К таким растениям относится гиностемма пятилистная (Gynostemma pentaphyllum (Thunb.) Makino) семейства тыквенные (Cucurbitaceae). Это многолетняя лиана с ежегодно возобновляющимися травянистыми побегами, снабженными усиками. Народные названия ее разнообразны: тайский чай, трава бессмертия, южный женьшень. Растение обладает тонкими лазающими стеблями, достигающими до 8 м в высоту, со сложными овально-эллиптическими зубчатыми листочками до 8 см длиной и 3 см шириной, покрытыми щетинками. Цветки зеленовато-желтые, мелкие, однополые, собранные в кистевидные соцветия, длиной до 15 см. Плоды шаровидные, черновато-зеленого цвета до 0,8 см в диаметре. Ареал произрастания гиностеммы охватывает тропические территории Китая, Кореи, Вьетнама, Индии, Японии и др. В России гиностемма пятилистная произрастает только на острове Кунашир и является эндемиком Дальнего Востока [1].

Несмотря на то, что гиностемма мало известна в России и не включена в список фармакопейных растений, она имеет уникальный химический состав и является потенциальным источником ценных биологически активных веществ. В ее сырье содержатся гинзенозиды, полисахариды, гликозиды, аминокислоты, флавоноиды, протеины, макро - и микроэлементы [2, 3, 4, 5]. Гиностемма пятилистная обладает гепатопротекторными, гипогликемическими, иммуномодулирующими, антиоксидантными, адаптогенными, противовоспалительными, цитотоксическими и др. фармакологическими свойствами. Отмечено ее положительное влияние на пищевую, сердечно-сосудистую, нервную, иммунную, репродуктивную системы организма, предполагается, что данное растение полезно для профилактики и лечения атеросклероза и для замедления старения организма $[6,7,8]$. Она широко используется в народной медицине азиатских стран. В традиционной китайской медицине это растение упоминается с 1400 года и считается, что по своему воздействию на человеческий организм схожа с женьшенем. В 1991 году по материалам Пекинской конференции по народной медицине гиностемма включена в список лучших тонизирующих трав. Для использования в лечебных целях заготавливается лист растения, который используется в форме настоев и чаев. В России гиностемма выпускается в качестве биологически активных добавок: чай Джиаогулан, композиция с арабиногалактаном из лиственницы Сибирской [9].

В связи с тем, что гиностемма - эндемическое растение, обеспечение фармацевтической промышленности отечественным сырьем не представляется возможным, решить эту проблему можно только за счет введения данного вида в культуру.

Первые исследования по интродукции гиностеммы начали проводиться в Башкирском государственном медицинском университете (г. Уфа) с целью изучения ее химического состава и стандартизации лекарственного сырья с использованием микроскопического метода анализа $[10,11]$. Опыт выращивания гиностеммы только в Уральском регионе недостаточен для определения наибо- лее перспективной почвенно-климатической зоны возделывания данной культуры, необходимо проведение широких интродукционных исследований в различных регионах России

В связи с этим в условиях Западного Предкавказья были заложены опыты, где изучались особенности роста и развития культуры, устанавливались сроки прохождения фенологических фаз, определялась урожайность лекарственного сырья и выявлялись наиболее оптимальные условия ее выращивания.

\section{Методы}

Methods

Исследования проводили в 2017-2020 годах на опытных полях лекарственного севооборота Северо-Кавказского филиала ФГБНУ ВИЛАР.

Полевые опыты проводили в соответствии с методиками, разработанными для лекарственных культур: «Методика исследований при интродукции лекарственных растений», «Требования к оформлению полевых опытов во Всероссийском научно-исследовательском институте лекарственных и ароматических растений (ВИЛАР)» [12, 13].

Почвы Западного Предкавказья - выщелоченные черноземы. Содержание гумуса в пахотном слое составляет 5,0\%, общего азота в пахотном горизонте - 0,22-0,30\%, фосфора $\left(\mathrm{P}_{2} \mathrm{O}_{5}\right)$ - 9,17-0,22\%, калия ( $\left.\mathrm{K}_{2} \mathrm{O}\right)-1,7-2,1 \%$. Верхние слои почв имеют нейтральную реакцию, $\mathrm{pH}$ водной вытяжки около 7\%.

Погодные условия проведения исследований отличались высокими температурами (июнь-август), превышающими среднемноголетние показатели на 3-70С, и недостатком осадков.

Размножение гиностеммы пятилистной осуществляли путем выращивания рассады из семян, полученных по договору из Южной Кореи.

Площадь опытной делянки 12 м², ширина междурядий 60 см, повторность опытов 4-х кратная.

Выращивание гиностеммы проводили в двух вариантах солнечного освещения: прямое и затенение, то есть выращивание под пологом деревьев, которые бросая тень, частично сокращали попадание прямых солнечных лучей на растения.

В процессе вегетации растений изучали фазы развития, ростовые процессы, проводили учет урожайности. Уборку урожая проводили в фазу бутонизации-начала цветения.

Экспериментальные данные обрабатывали по Б.А. Доспехову.

\section{Результаты и обсуждения}

Results and discussions

Гиностемма пятилистная - это вьющаяся лиана с ползучим стеблем и побегами, поэтому ее выращивали как шпалерную культуру. Фото растения представлено на рис. 1.

Семена гиностеммы отличаются низкой всхожестью - 34\%, проведение стратификации позволяет повысить их всхожесть до 35-37\%. В связи с низкой всхожестью семян, размножение гиностеммы осуществляли путем выращивания рассады в тепличном комплексе с последующей ее высадкой в полевые условия. Посев семян в почвенную смесь проводили во второй декаде марта, первые всходы появились через 37-40 суток после посева, настоящие 


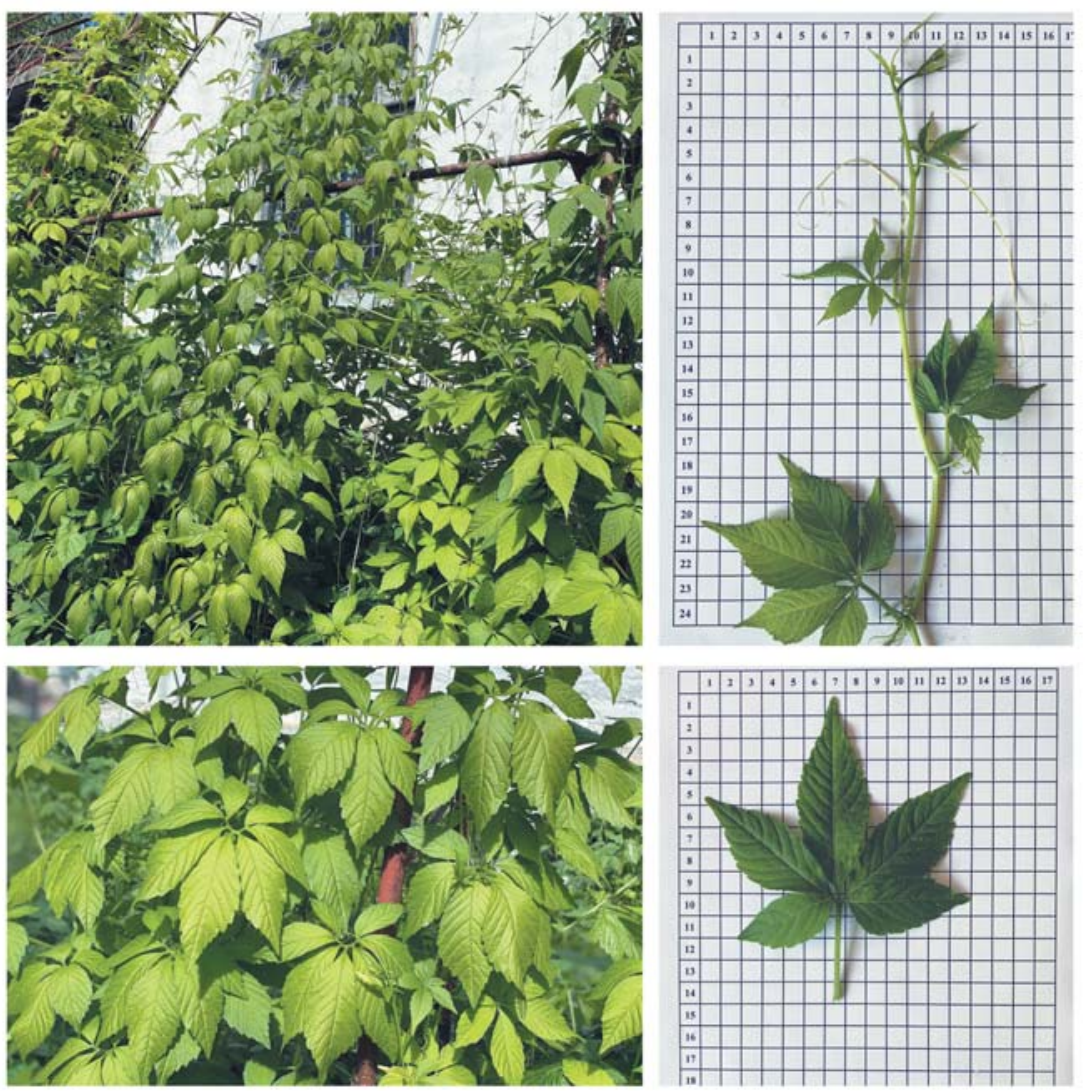

Рис. 1. Гиностемма пятилистная второго года вегетации Fig. 1. Gynostemma pentaphyllum (Thunb.) Makino of the second year of vegetation

листья - в первой декаде мая. Посадку рассады в полевые условия начали в конце первой-начале второй декад мая.

Наблюдения за ростом и развитием гиностеммы показали, что растения проходят все фенологические фазы, начиная с первого года вегетации. Соответствующие данные представлены в таблице 1. Как видно из данных таблицы, фаза бутонизации гиностеммы на первом году вегетации наступает в первой декаде августа и продолжается до конца месяца, фаза цветения растянута от 68 до 73 суток. Уже в первый год вегетации растения дают плоды, созревание которых неодновременное, начинается со второй декады октября и длится до первых заморозков. Продолжительность вегетационного периода гиностеммы на первом году вегетации составляет 229 суток.

На втором и третьем годах вегетации гиностеммы, по данным фенологических наблюдений, отрастание растений наблюдается в I - II декадах апреля, наиболее раннее отмечено 03.04., позднее - 14.04. Бутонизация наступает в июле, самое раннее ее начало отмечено 04.07, позднее 29.07., продолжительность данной фазы составляет $24,7 \pm 2,3$ суток. Цветение гиностеммы растянуто, с первой декады августа до первой декады октября, всего - 64,2 26,5 суток. Наиболее ранний срок цветения - 02.08., поздний 08.10. В конце сентября начинается созреванием семян, в октябре - их уборка. Общий срок вегетационного периода второго и третьего годов вегетации культуры в среднем составляет $238,4 \pm 11,6$ суток.

Наблюдения за растениями гиностеммы показали, что прямое солнечное освещение, высокие температуры и низкий уровень влажности воздуха в период интенсивного роста оказались неблагоприятными для роста и развития растений, наблюдалось некоторое их угнетение и более бледная окраска листьев. Даже обильный полив не способствовал интенсификации ростовых процессов. Вполне возможно, что гиностемма, как и женьшень, не переносит прямые солнечные лучи и требует некоторого затенения. В связи с этим были заложены опыта по выращиванию гиностеммы на прямом солнечном свете и при затенении.

Как показывают данные таблицы 2, высота растений в обоих вариантах опыта увеличивается от первого к третьему году вегетации. Однако, при затенении наблюдается более интенсивный прирост (таб.2).

Наибольшие различия отмечаются по массе растений, в варианте с затенением этот показатель значительно выше, чем при ярком солнечном свете, где наблюдается ее снижение от первого к третьему году вегетации (см. табл. 2). Это связано с тем, что при затенении значительно увеличивается площадь листьев, что хорошо видно на рис. 2.

Кроме того, на корневище гиностеммы пятилистной на II и III годах вегетации, особенно при затенении, образуются новые дополнительные побеги (см. рис. 3). Их количество на растениях при ярком солнечном свете на II г.в.

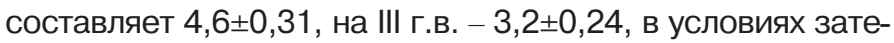
нения эти показатели значительно выше $-9,7 \pm 0,47$ и $11,0 \pm 0,52$, соответственно.

Усиление роста и развития гиностеммы при затенении приводит и к значительному приросту урожайности, особенно на третьем году вегетации культуры, по сравнению с ярким солнечным светом (табл. 2). В то же время все хозяйственно ценные показатели гиностеммы, выращенной на ярком солнечном свете, снижаются: высота растений - на 24-49\%, масса растений - на 16-56\% и урожайность - на $24-49 \%$ (рис. 3).

Таким образом, для получения высоких урожаев лекарственного сырья гиностеммы пятилистной важно соблюдать условия ее выращивания, то есть обязательное притенение. 


\section{ЛУГОВОДСТВО И ЛЕКАРСТВЕННЫЕ ЭФИРОМАСЛИЧНЫЕ КУЛЬТУРЫ}

Таблица 1. Фенологический спектр гиностеммы пятилистной первого-третьего годов вегетации в условиях Западного Предкавказья

Table 1. Phenological spectrum of Gynostemma pentaphyllum (Thunb.) Makino of the first-third years of vegetation in the conditions of the Western Caucasus

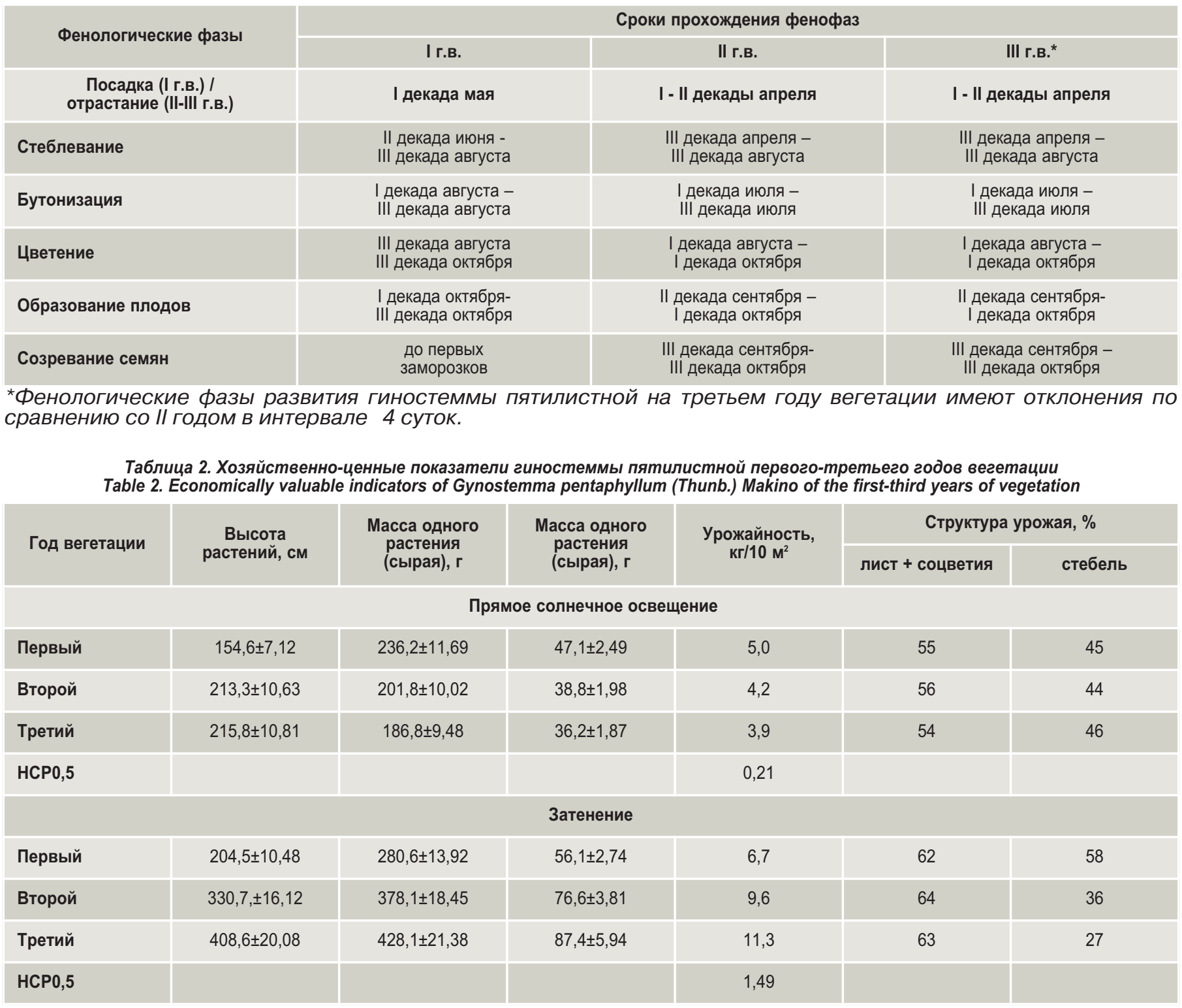

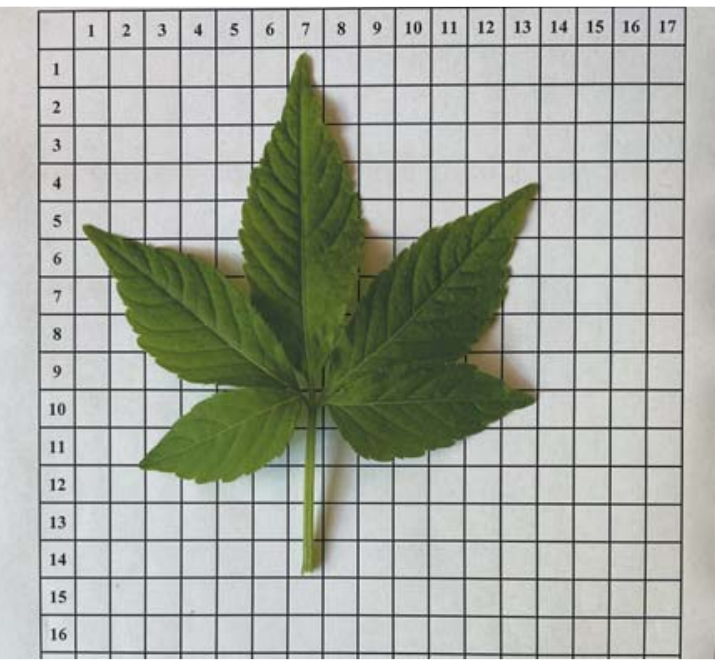

Лист с растений гиностеммы, выращенной на прямом солнечном свету

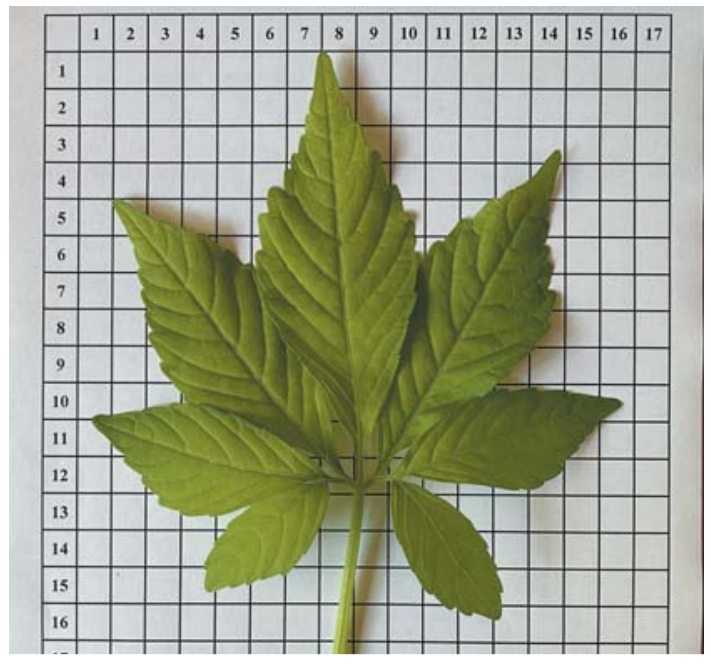

Лист с растений гиностеммы, выращенной при затенении 


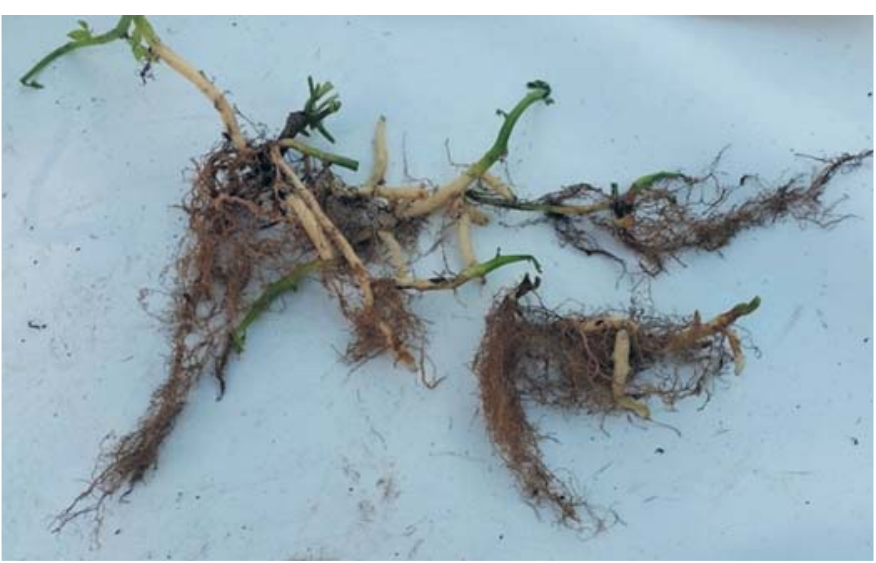

Рис. 3. Корневая система гиностеммы

пятилистной с побегами второго года вегетации

Fig. 3. Root system of the

Gynostemma pentaphyllum (Thunb.)

Makino with shoots of the second year of vegetation

\section{Заключение}

\section{Conclusion}

Проведенные интродукционные исследования с гиностеммой пятилистной свидетельствуют о возможности ее культивирования в условиях Краснодарского края.

В условиях культуры установлены сроки прохождения фенологических фаз растений I - III годов вегетации, определена продолжительность вегетационного

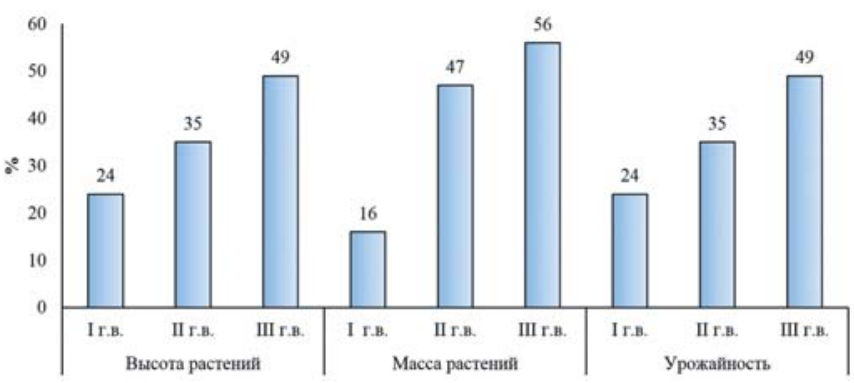

Рис. 4. Снижение хозяйственно ценных показателей гиностеммы в условиях прямого солнечного освещения по сравнению с притенением

Fig. 4. Reduction of economically valuable indicators of Gynostemma pentaphyllum (Thunb.) Makino in direct sunlight compared to shading

периода от 229 до 238 суток.

Показано, что в условиях Западного Предкавказья растения гиностеммы проходят полный цикл развития.

Установлено, что оптимальным условием при возделывании культуры является притенение, так как выращивание ее при прямом солнечном освещении приводит к снижению всех хозяйственно ценных показателей.

\section{Об авторах:}

Виталий Рамазанович Тхаганов - старший научный сотрудник Татьяна Васильевна Мироненко - младший научный сотрудник, mironenkoau83@mail.ru

Татьяна Геннадьевна Кадацкая - агроном

\section{About the authors:}

Vitaly R. Tkhaganov - Senior Researcher

Tatiana V. Mironenko - Junior Researcher

Tatiana G. Kadatskaya - agronomist

\section{- Литература}

1. Сосудистые растения советского Дальнего Востока. Под редакцией С.С. Харкевич. Л.: Наука, 1985;(2):136.

2.Беленковская Л.М., Буданцева А.Л., Битюкова Н.В. Gynostemma pentaphyllum (Cucurbitaceae); компонентный состав и биологическая активность. Растительные ресурсы. 2018:(54):443-495. DOI: 10.1134/S0033994618040015 (In Russ.)

3. Cipriani T.R., Mellinger C.G., de Souza L.M. A Polysaccharide from a tea (Infusion) of Maytenus ilicifolia leaves with anti-ulcer protective effects. J Nat Prod. 2006;(69):1018-1021.

4.Низамова, А.А., Игзакова 3.И., Галиахметова Э.Х., Кудашкина Н.В., Хасанова C.P. Полисахариды травы гиностеммы пятилистной (Gynostemma pentaphyllum (Thunb)).Традищионная медищина. 2020;2(61):36-39.

5. Низамова А.А., Галиахметова Э.Х., Кудашкина Н.В. Исследование флавоноидов травы гиностеммы пятнистой (Gynostemma pentaphyllum (Thunb)) Сборник трудов седьмой научной конференции "Современные тенденции развития технологий здоровьесбережения». М.: ВИЛАР 2019. Р.268-272

6. Wang Z.J. Antioxidant activities of different fractions of polysaccharide puried from Gynostemma pentaphyllum Makino. Carbohydrate Polymers. 2007;(68):54-58 7. Yan W., Niu Y., Lv J., Xie Z. Characterization of a heteropolysaccharide isolated from diploid Gynostemma pentaphyllum Makino. Carbohydr. Polym. 2013; Feb.3. T.92 (2). P. 2111-2117.

8. Circosta, C, Pasquale R. De, Occhiuto F. Cardiovascular effects of the aqueous extract of Gynostemma pentaphyllum Makino. Phytomedicine. 2005;(12):638-643. 9. Душкин А.И., Верещагин Е.И., Душкин М.И. и др. Композиция с повышенной фармакологической активностью на основе гиностеммы пятилистной. Патент № RU 2568883 C2 . 2015r.

10. Низамова А.А., Галиахметова Э.Х., Кудашкина Н.В. Изучение биологической активности листьев гиностеммы пятилистной (Gynostemma pentaphyllum (Thunb) Mokino), индуцированной на территории республики Башкортостан. Лекарственное растениеводство: от опыта прошлого к современным технологиям. Материалы шестой Международной научно-практической конференции. Полтава: 2017. С.177-178.

11. Низамова А.А., Галиахметова Э.Х. Стандартизация листьев листьев гиностеммы пятилистной (Gynostemma pentaphyllum (Thunb.), индуцированной на территории республики Башкортостан, с использованием микроскопического метода исследования. Фармация. 2017;(S):726-729.

12. Майсурадзе Н.И., Киселев В.П., Черкасов О.А. и др. Методика исследований при интродукции лекарственных растений. Обзорная информация. Сер. Лекарственное растениеводство. М.: ЦБНТИ Медпром. 1984;(3):1-32.

13. Требования к оформлению полевых опытов во Всероссийском научноисследовательском институте лекарственных и ароматических растений. М. ВИЛАР; 2006.

\section{- References}

1. [Vascular plants of the Soviet Far East]. Responsible editor Xarkevich S.S. Leningrad: Nauka, 1985;(2):136 (In Russ.)

2. Belenkovskaya L.M., Budantseva A.L., Bityukova N.V. [Gynostemma pentaphyllum (Cucurbitaceae); component composition and biological activity] Rastitelnye resursy 2018:(54):443-495 (In Russ) 10.1134/S0033994618040015

3. Cipriani T.R., Mellinger C.G., de Souza L.M. A Polysaccharide from a tea (Infusion) of Maytenus ilicifolia leaves with anti-ulcer protective effects. J Nat Prod. 2006;(69):1018-1021.

4. Nizamova A.A Igzakova Z. I., Galiaxmetova E X Kudashkina N.V., Xasanova S.R. [Polysaccharides of the herb Gynostemma pentaphyllum]. Traditsionnaya meditsina. 2020;2(61):36-39. (In Russ.)

5. Nizamova A.A., Galiakhmetova EH.KH., Kudashkina N.V. [The study of flavonoids in the raw materials of the Gynostemma pentaphillum]. Sbornik trudov sed'moi nauchnoi konferentsii "Sovremennye tendentsii razvitiya tekhnologii zdorov'esberezheniya». Moscow: VILAR; 2019. P.268-272 (In Russ.).

6. Wang Z.J. Antioxidant activities of different fractions of polysaccharide puried from Gynostemma pentaphyllum Makino. Carbohydrate Polymers. 2007;)68):54-58 7. Yan W., Niu Y., Lv J., Xie Z. Characterization of a heteropolysaccharide isolated from diploid Gynostemma pentaphyllum Makino. Carbohydr. Polym. 2013 Feb.3. T.92 (2). P. 2111-2117

8. Circosta, C, Pasquale R. De, Occhiuto F. Cardiovascular effects of the aqueous extract of Gynostemma pentaphyllum Makino. Phytomedicine. 2005;(12):638-643.

9. Dushkin A.I. Vereshchagin, M.I. Dushkin et al. Gynostemma pentaphyllum composition with high pharmacologicalactivity: patent of the Russian Federation №2013114221/15; application 28.03.2013; publ. 20.11.2015.

10. Nizamova A.A., Galiakhmetova EH.KH., Kudashkina N.V. [The study of biological activity leaves gynostemma pentaphyllum (Gynostemma pentaphyllum (Thunb.) Makino) introduced in the territory of the Republic of Bashkortostan] Lekarstvennoe rastenievodstvo: ot opyta proshlogo $k$ sovremennym tekhnologiyam. Materialy shestoi Mezhdunarodnoi nauchno-prakticheskoi konferentsii. Poltava: 2017. P.177-178. (In Russ.).

11. Nizamova A.A., Galiakhmetova EH.KH. [Standardization of leaves of gynostemma pentaphyllum, introduced on the territory of the Republic of Bashkortostan microscopic method]. Farmatsiya. 2017;(S):726-729. (In Russ.).

12. Majsuradze N.I., Kiselev V.P., CHerkasov O.A. et al. [Research methodology for the introduction of medicinal plants]. Lekarstvennoe rastenievodstvo. Obzornaya informatsiya. TSBNTI. Moscow: Medprom; 1984;(3):1-32. (In Russ.).

13. [Requirements for the design of field experiments at the All-Russian Scientific Research Institute of Medicinal and Aromatic Plants]. Moscow: VILAR; 2006. (In Russ.). 